\title{
Role of Duplex Color Doppler Study of Uterine Artery in the Early Diagnosis of Preeclampsia in Pregnant Women
}

\author{
Sohely Sultana, ${ }^{1}$ Tarana Yasmin, ${ }^{2}$ Md. Nazir Uddin Mollah, ${ }^{3}$ Shyamal Kumar Roy, ${ }^{4}$ Mohammad Sazzad Hossain, ${ }^{4}$ \\ Umme Iffat Sultana ${ }^{5}$
}

\begin{abstract}
Background: Duplex Colour Doppler Sonography is gaining increasing popularity for assessment of blood vessels in various disease processes around the world as well as for the surveillance of fetus compromised by intra uterine growth retardation (IUGR) and to assess foetal structural abnormalities and complex disease processes.

Materials \& methods: This cross sectional study was carried out to observe Doppler wave form in subjects with preeclampsia enrolling 40 subjects with preeclampsia, in the Department of Radiology and Imaging, Dhaka Medical College Hospital, Dhaka, over a period of six months from $20^{\text {th }}$ May 2012 to $19^{\text {th }}$ November 2012.A total number of 40 normal pregnancies were also included for comparison. Peak systolic velocity (PSV), end diastolic velocity (EDV), Resistive index (RI), Pulsatility index (PI) in different groups of study subjects from 24th to 37th weeks were observed and compared for any significant differences.

Results: Majority (35\% in normal and $37.5 \%$ in preeclampsia) of the respondents were found in the age group of 2I-30 years. Unpaired t-test revealed no significant difference between mean age between two groups. Among normal group, mean $\pm S D$ PSV, EDV, PI and RI were $43.94 \pm 15.41 \mathrm{~cm} / \mathrm{sec}$ and $15.51( \pm 4.93) \mathrm{cm} / \mathrm{sec}$, $I .12 \pm 0.0846$ and $0.57 I( \pm 0.058)$ respectively. Mean PSV, EDV, $P I$ and $R I$ were $83.19 \pm 18.44 \mathrm{~cm} / \mathrm{sec}, 11.86 \pm 5.19$ $\mathrm{cm} / \mathrm{sec}, 2.497 \pm 0.369$ and $0.8255 \pm 0.087$ in preeclampsia group. There was statistically significant (By unpaired $t$ test) difference in mean Doppler indices between these two groups. It was observed that early diastolic notch was found in $90 \%$ subjects with preeclampsia. Early diastolic notch was observed in Doppler wave form in $5 \%$ subject with normal pregnancy. Chi-square test showed that there was statistically significant difference in presence of early diastolic notch between normal subjects and subjects with preeclampsia.
\end{abstract}

Conclusions: From the study result it was concluded that Doppler indices with presence of early diastolic notch are reliable indicators for early detection of preeclampsia.

Keywords: Duplex Color Doppler, Uterine Artery, Preeclampsia, Pregnant Women

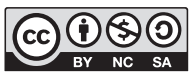

DOI: https://doi.org/I0.3329/jom.v20i2.42008

Copyright: (C) 2019 Sultana $S$ et al. This is an open access article published under the Creative Commons Attribution-NonCommercial-NoDerivatives 4.0 International License, which permits use, distribution and reproduction in any medium, provided the original work is properly cited, is not changed in any way and it is not used for commercial purposes.

Received: 25 February, 2019;

Accepted: 09 June, 2019

Introduction:

Among the various imaging tools in the department of Radiology and Imaging, use of Duplex Colour Doppler

1. Ex Senior Registrar, Department of Radiology \& Imaging, Apollo Hospitals Dhaka.

2. Associate Professor, Department of Radiology \& Imaging, Enam Medical College \& Hospital, Dhaka.

3. Associate Professor, Dept. of Oncology, BSMMU, Dhaka.

4. Assistant Professor, Department of Radiology \& Imaging, Sir Salimullah Medical College \& Mitford Hospital, Dhaka.

5. Assistant Professor, Department of Radiology \& Imaging, Khwaja Yunus Ali Medical College \& Hospital, Sirajganj.

Corresponding author: Dr. Sohely Sultana, Ex Senior Registrar, Department of Radiology \& Imaging, Apollo Hospitals Dhaka. Email: sohelysumi1@gmail.com.
Sonography is gaining increasing popularity for assessment of blood vessels in various disease processes around the world. The past 20 years have seen an enormous growth in both technical aspects of Doppler ultrasound and its application in obstetric and foetal medicine. Vessel assessment is now much easier than ever before without involvement of radiation and contrast media. Doppler ultrasound has important screening and diagnostic capabilities. ${ }^{1-3}$ In addition Doppler ultrasound has an important contribution to the surveillance of fetus compromised by intra uterine growth retardation (IUGR) and to assess foetal structural abnormalities and complex disease processes $1,3,4,5$. Spectral wave of the uterine artery and vein can usually be easily obtained by using Doppler ultrasound. ${ }^{2,6}$ Furthermore; the uterine artery notch can be made visible 
through this ultrasound which is found significantly associated with higher risk of preeclampsia and also in general pregnant population ${ }^{7}$.

Several studies show Doppler ultrasound in first trimester does not have any impact on pregnancy outcome. But Doppler ultrasound in $2^{\text {nd }}$ and $3^{\text {rd }}$ trimester play vital role in determining foetal outcome. Doppler wave form showing increased resistance to flow in $2^{\text {nd }}$ and $3^{\text {rd }}$ trimesters are associated with poor pregnancy outcome ${ }^{3}$. For this Continuous Wave Doppler, Pulsed Doppler, Color Flow, Powered Doppler are utilized to measure PSV, EDV, PI, RI, and systolic to diastolic velocity $(\mathrm{S} / \mathrm{D})$ ratio. ${ }^{4,8}$

Despite recent advances in antenatal care, pre-eclampsia has remained a major cause of maternal and perinatal morbidity and mortality. Hypertension in pregnancy is responsible for $18 \%$ of fetal (> 19 weeks of gestation) and infant mortality and $46 \%$ of infants born small for gestational age. ${ }^{9,10}$ Early screening for preeclampsia may allow vigilant antenatal surveillance and appropriate timing of fetal delivery in order to avoid serious sequelae. Unfortunately, various haemodynamic and biochemical measures have been found to have limited accuracy as screening measures for this condition.

Pre-eclampsia is characterized by an imbalance between prostacycline and thromboxane production ${ }^{5}$ as well as failure of the second wave trophoblastic invasion of the endometriomyometrial vasculature. The result is abnormal uteroplacental blood flow, and this has led to the idea of using Doppler assessment of uterine artery velocity waveforms as a method of screening for this antenatal complication. ${ }^{6}$ An abnormal test result is represented by either an abnormal flow velocity ratio (systolic to diastolic velocity (S/D) ratio, diastolic to systolic velocity ratio $(\mathrm{S} / \mathrm{D})$ or resistance index or the presence of an early diastolic notch. ${ }^{11-13}$

Study also carried out for early diagnosis of preeclampsia (PET) by measuring uterine artery pulsatility index (PI) at 11 weeks to 13 weeks 6 days' gestation. A more effective method of screening for PET is provided by uterine artery Doppler velocimetry at 22 weeks' gestation either alone or in combination with maternal history, with detection rates of $52 \%$ and $57 \%$, respectively. Indeed, Doppler is particularly effective in screening for severe PET that necessitates iatrogenic delivery before 34 weeks, with a detection rate of $85 \%$ for a false-positive rate of $10 \%$.

Identification of women at high risk for PET during the second trimester could potentially improve pregnancy outcome because intensive maternal and fetal monitoring in such patients would lead to an earlier diagnosis of the clinical signs of the disease and the associated fetal growth restriction and avoid the development of serious complications through such interventions as the administration of antihypertensive medication and early delivery.

No previous study regarding the Doppler sonography of uterine artery had been carried out in our country on preeclampsic mother. So this present study was carried out to observe Doppler wave form in subjects with preeclampsia. However, the wide variation in scanning techniques, Doppler measurement parameters and study protocols have resulted in conflicting results. ${ }^{14}$

If we can sonologically help the pregnant women in the early detection and management of pre-eclampsia this study will help reduce the mortality from this widely prevalent problem in our country and as well as will help the policy makers to design national health measures guided against this fatal entity.

Anatomy of uterine artery: The uterine artery usually arises from the anterior division of the internal iliac artery. It travels to the uterus, crossing the ureter anteriorly, reaching the uterus by traveling in the cardinal ligament. It travels through the parametrium of the inferior broad ligament of the uterus. It commonly anastomoses (connects with) the ovarian artery. The uterine artery is the major blood supply to the uterus and enlarges significantly during pregnancy. ${ }^{9}$

Abnormal uterine flow in preeclampsia: Pregnancies affected by the complications of impaired placentation such as pregnancy induced hypertension had been shown to demonstrate increased impedance in the spiral artery. ${ }^{4}$ In subjects with preeclamsia arterial resistance is increased. ${ }^{1 \text {, }}$ 10, 13-16 This results in increase in PSV and decrease in EDV. Aardema et al ${ }^{16}$ observed that a striking difference between PI values for $\mathrm{PIH} / \mathrm{PE}$ with and without poor pregnancy outcome. Uterine artery PI in the 22nd week was increased significantly in pregnancies which developed early-onset (before 35 weeks) PIH/PE with a poor pregnancy outcome. Coleman et al ${ }^{18}$ had seen that RI value was e" 0.7 in subjects with preeclampsia. North et $\mathrm{al}^{17}$ found that majority of the preeclampsic women had early diastolic notch in their uterine artery Doppler.

\section{Materials and methods:}

This present cross sectional study was carried out to observe Doppler wave form in 40 subjects with preeclampsia in the Department of Radiology and Imaging, Dhaka Medical College Hospital, Dhaka during May to November, 2012. 
Sampling technique was purposive. A total number of 40 normal pregnancies were included for comparison. Doppler indices of uterine artery were measured by researcher herself first and subsequently assessed by two consultant radiologists of the Department who did not know the patient's history to eliminate observation bias.

Clinical examination and laboratory tests were done and data collected. Demographic information was prospectively recorded and substantiated by means of inspection of medical record. Information included was the subject's age, medical and clinical history, followed by conduction of the study. No preparation was required before examination. Uterine artery was examined with $3-5 \mathrm{MHz}$ curvilinear transducer in Siemens Sonoline 8000. The Doppler velocimetry measurements of the uterine artery were taken at the point just distally to the crossover with the iliac artery, before uterine artery division into arcuate arteries. The Doppler indices of uterine artery taken as outcome variables are PSV, EDV, PI, RI and Early diastolic notch.

Data were collected in a pre-designed structured data collection sheets. Data were collected from primary source starting from the clinical history to laboratory investigations. The results were presented in tables, figures, diagrams etc. Data entry and analysis were done using SPSS for windows version 19.0. Output of data and graphical representation was done using Microsoft Office chart and Microsoft-Word.

\section{Results:}

Age distribution of the study subjects

The age was ranged from 18 to 42 years in normal subjects and 18 to 43 years in subjects with preeclampsia. Majority ( $35 \%$ in normal and $37.5 \%$ in preeclampsia) of the respondents were found in the age group of $21-30$ years. $32.5 \%$ and 22.5 percent subjects were found below 20 years age group in normal and preeclampsia. T-test revealed no significant difference between mean ages between two groups (Fig-1).

Pulsatility index $(P I)$ of the study subjects

Among normal group, mean $( \pm$ SD) PI was $1.12( \pm 0.0846)$. PI ranged from 0.942 to 1.245 . Mean PI was 2.497 with SD of 0.369 in preeclampsia group. PI ranged from 2.193 to 2.193 in this group. There was statistical significant difference between mean PI between these two groups which was seen by t-test (Fig-2).

Resistive index $(R I)$ of the study subjects

Among normal group, mean $( \pm \mathrm{SD}) \mathrm{RI}$ was $0.571( \pm 0.058)$. RI ranged from 0.516 to 0.642 . Mean RI was 0.825 and SD was 0.087 in preeclampsia group. RI ranged from 0.745 to 0.745 in this group. There was statistical significant (By t-test) difference between mean RI between these two groups (Fig-3).

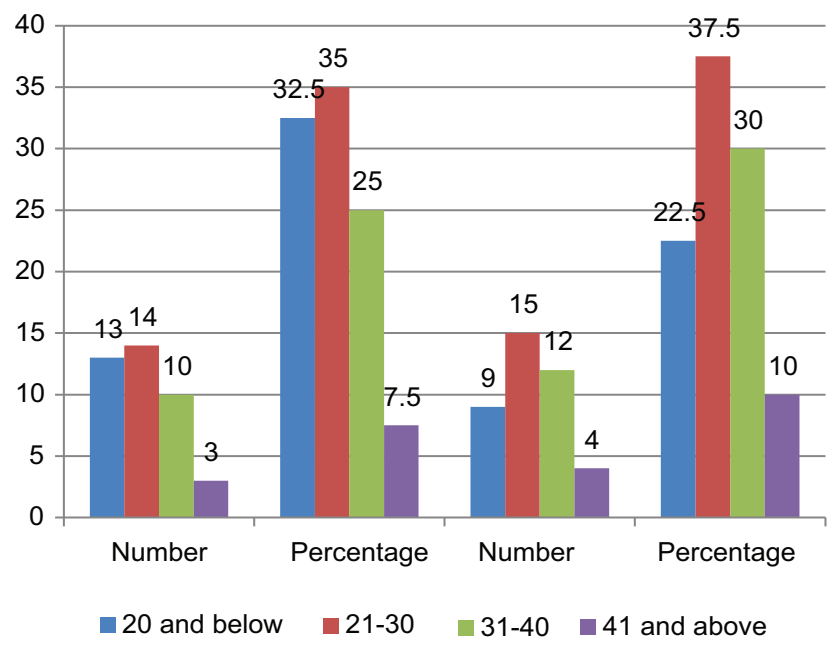

Figure 1: Age distribution of the study subjects

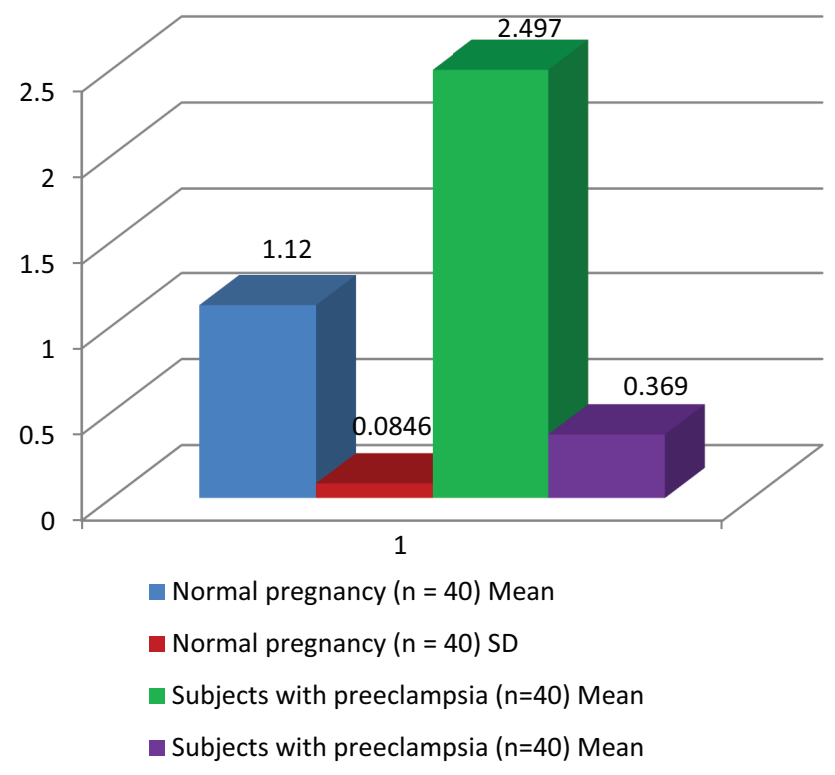

Figure 2: Pulsatility index of the study subjects

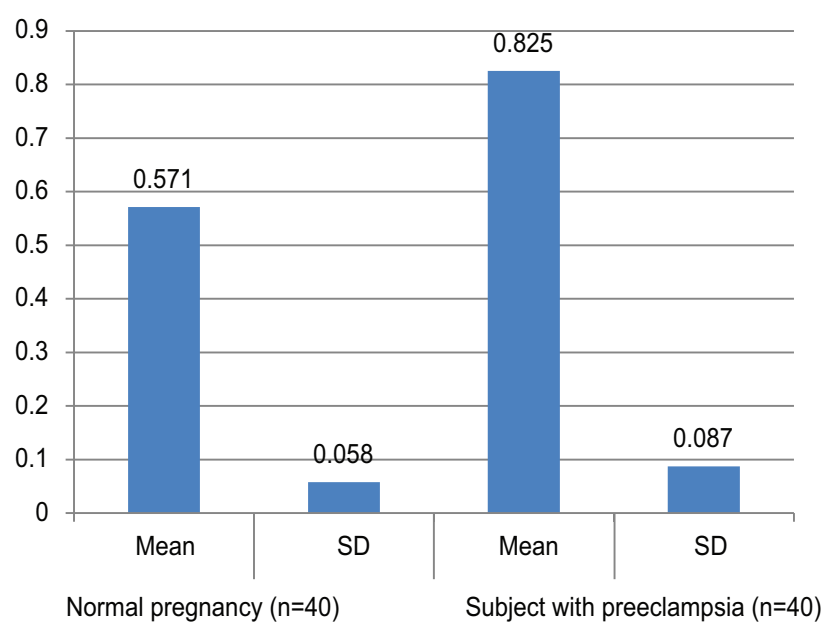

Figure 3: Resistive index of the study subjects 
Distribution of the study subjects by presence of early diastolic notch

It was seen that early diastolic notch was found in $36(90 \%)$ subjects with preeclampsia while in only $2(5 \%)$ subjects with normal pregnancy. Chi-square test showed that there was statistical significant difference in presence of early diastolic notch between two groups (Table-I).

Table I: Distribution of the study subjects by presence of early diastolic notch

\begin{tabular}{lclccc}
\hline \multicolumn{2}{l}{ Normal pregnancy $(\mathrm{n}=40)$} & & \multicolumn{2}{c}{ Subjects with preeclampsia $(\mathrm{n}=40)$} \\
\cline { 1 - 2 } \cline { 5 - 6 } Number & Percentage & & Number & Percentage Statistical test \\
\hline 36 & 90 & & 02 & 05 & 0.001 \\
\hline
\end{tabular}

- Statistical test was done by unpaired t-test

- Level of significance was considered at 0.05 level

\section{Discussion:}

Pre-eclampsia (PET), which affects about $2 \%$ of pregnancies, is a major cause of perinatal and maternal morbidity and mortality. ${ }^{1-3}$ Routine antenatal care has evolved with the aim of identifying women at high risk for subsequent development of PET. The likelihood of developing PET is increased by a number of factors in the maternal history, including Afro-Caribbean race, nulliparity, high body mass index (BMI) and personal or family history of PET. ${ }^{5}$ However, screening by maternal history may detect only about $30 \%$ of those that will develop PET for a false-positive rate of $10 \%{ }^{6}$ A more effective method of screening for PET is provided by uterine artery Doppler velocimetry at 22-24 weeks' gestation either alone or in combination with maternal history, with detection rates of $52 \%$ and $57 \%$, respectively. ${ }^{4,5,10}$ Indeed, Doppler is particularly effective in screening for severe PET that necessitates iatrogenic delivery before 34 weeks, with a detection rate of $85 \%$ for a false-positive rate of $10 \% .{ }^{11}$ Identification of women at high risk for PET during the second trimester could potentially improve pregnancy outcome .

This present cross sectional study was carried out to observe Doppler wave form in subjects with preeclampsia among 40 preelampsic and 40 normal pregnant subjects. The age was ranged from 18 to 42 years in normal subjects and 18 to 43 years in subjects with preeclampsia. Indeed this age range of the pregnant women is common in Bangladesh. Majority ( $35 \%$ in normal and $37.5 \%$ in preeclampsia) of the respondents were found in the age group of 21-30 years.

In subjects with preeclamsia arterial resistance is increased. ${ }^{1 \text {, }}$ 10,13-16 This results in increase in PSV and decrease in EDV. Similar comparable findings were seen in present study.
Among normal group, mean \pm SD PSV was $43.94 \pm 15.41 \mathrm{~cm} /$ sec. PSV ranged from $28.1 \mathrm{~cm} / \mathrm{sec}$ to $63.23 \mathrm{~cm} / \mathrm{sec}$. Mean PSV was $83.19 \mathrm{~cm} / \mathrm{sec}$ and SD was $18.44 \mathrm{~cm} / \mathrm{sec}$ in preeclampsia group. PSV ranged from $65.29 \mathrm{~cm} / \mathrm{sec}$ to 95.37 $\mathrm{cm} / \mathrm{sec}$ in this group. There was statistical significant difference between mean PSV between these two groups. Mean $( \pm \mathrm{SD})$ PSV was $15.51( \pm 4.93) \mathrm{cm} / \mathrm{sec}$. PSV ranged from $10.7 \mathrm{~cm} / \mathrm{sec}$ to $23.5 \mathrm{~cm} / \mathrm{sec}$ among normal group. Mean PSV was $11.86 \mathrm{~cm} / \mathrm{sec}$ and SD was $5.19 \mathrm{~cm} / \mathrm{sec}$ in preeclampsia group. PSV ranged from $6.82 \mathrm{~cm} / \mathrm{sec}$ to $18.79 \mathrm{~cm} / \mathrm{sec}$ in this group. Statistical significant difference between mean EDV was seen between these two groups.

Pregnancies affected by the complications of impaired placentation such as pregnancy induced hypertension had been shown to demonstrate increased impedance in the spiral artery. ${ }^{4}$ This was reflected in our study that Mean \pm SD PI was $1.12 \pm 0.0846$ among subjects with normal pregnancy and Mean PI were 2.497 with SD of 0.369 in preeclampsia group. There was also statistical significant difference between mean PI between these two groups which was seen by ttest. Aardema et al ${ }^{16}$ found the similar study result. They observed that a striking difference between PI values for $\mathrm{PIH} / \mathrm{PE}$ with and without poor pregnancy outcome. Uterine artery PI in the 22nd week was increased significantly in pregnancies which developed early-onset (before 35 weeks) $\mathrm{PIH} / \mathrm{PE}$ with a poor pregnancy outcome.

The spiral artery, the major continuation of the uterine artery undergoes trophoblastic invasion during pregnancy. This physiological process is characterized by loss of the musculoelastic properties and its conversion to the uteroplacental arteries, which allows an increased blood flow to the placenta and the fetus. This process commences in the first and ends in early second trimester. ${ }^{8}$ Second trimester Doppler is usually performed between 20th and 24th weeks of pregnancy, when it is expected that the physiologic process would have been completed. The impairment or complete absence of the physiological process is associated with increased vascular resistance to blood flow and ultimately affect blood flow into the placenta. ${ }^{9-11}$ This phenomenon was reflected in this present study. In present study, mean $( \pm \mathrm{SD}) \mathrm{RI}$ was $0.571( \pm 0.058) \mathrm{cm} / \mathrm{sec}$ in normal subjects while it was increased in case of preeclampsia. Mean RI was 0.825 and SD was 0.087 in preeclampsia group. In a comparable study by Coleman et a ${ }^{18}$ it was observed that RI value was e" 0.7 in subjects with preeclampsia. It was seen that early diastolic notch was found $36(90 \%)$ subjects with preeclampsia. Early diastolic notch was observed in Doppler wave form in $2(5 \%)$ subjects. North et al ${ }^{17}$ found that majority of the preeclampsic women had early diastolic notch in their 
uterine artery Doppler. Harrington et $\mathrm{l}^{15}$ performed two mid pregnancy screening studies of antenatal population in the last three years, to assess the use of Doppler velocimetry studies at that time in predicting the subsequent development of PPIH. There was a significant association between an abnormal RI and the subsequent development of PPIH. There was presence of a pre diastolic notch as well as an elevated RI in preeclampsic subjects.

\section{Conclusions:}

From the present study it was observed that mean \pm SD PSV, EDV was $83.19 \pm 18.44 \mathrm{~cm} / \mathrm{sec} 15.51 \pm 4.93 \mathrm{~cm} / \mathrm{sec}$ respectively in preeclampsic group. Mean \pm SD PI was $1.12 \pm 0.0846$ and mean $( \pm$ SD) RI was $0.571( \pm 0.058) \mathrm{cm} / \mathrm{sec}$. There was statistical significant (By t-test) difference between mean PSV, EDV, PI and RI between preeclampsic and normal subjects. It was revealed that early diastolic notch was found 36 (90\%) subjects with preeclampsia. So, these Doppler indices with presence of early diastolic notch are reliable indicator for early detection of preeclampsia.

\section{Conflict of interest: None.}

\section{References:}

1. World Health Organization. Make every mother and child count. World Health Report, 2005. WHO: Geneva, 2005.

2. Royal College of Obstetricians and Gynaecologists (RCOG). Why mothers die 2000-2002: the sixth report of confidential enquiries into maternal deaths in the United Kingdom, Lewis G ( $3^{\text {rd }}$ ed.). RCOG Press: London, 2004.

3. ACOG Committee on Practice Bulletins - Obstetrics. ACOG practice bulletin: diagnosis and management of pre-eclampsia and eclampsia. Obstet Gynecol 2002; 99: 159-67.

4. National Collaborating Centre for Women's and Children's Health. Commissioned by the National Institute for Clinical Excellence. Antenatal care: Routine care for the healthy pregnant woman. Clinical Guideline: October 2003.

5. Yu CK, Smith GCS, Papageorghiou AT, Cacho AM, Nicolaides KH. An integrated model for the prediction of pre-eclampsia using maternal factors and uterine artery Doppler velocimetry in unselected low-risk women. Am J Obstet Gynecol 2005;193:429-36.

6. Campbell S, Diaz-Recasens J, Griffin DR, Cohen-Overbeek TE, Pearce JM, Willson K, Teague MJ. New Doppler technique for assessing uteroplacental blood flow. Lancet 1983;26: 675-77.

7. Ibukun AA, Oluwagbemiga A, Bukunmi MI, Adeniyi SA, Olabisi ML. Uterine artery Doppler velocity in hypertensive disorder of pregnancy in Nigeria. J ultrason 2017;17:253258.
8. Villar J, Abdel-Aleem H, Merialdi M, Mathai M, Ali MM, Zavaleta N, Purwar M, Hofmeyr J, Nguyen TN, Campodonico L, Landoulsi S, Carroli G, Lindheimer M; World Health Organization Calcium Supplementation for the Prevention of Preeclampsia Trial Group. World Health Organization randomized trial of calcium supplementation among low calcium intake pregnant women. Am J Obstet Gynecol 2006;194:639-49.

9. Rumbold AR, Crowther CA, Haslam RR, Dekker GA, Robinson JS, ACTS Study Group. Vitamins $\mathrm{C}$ and $\mathrm{E}$ and the risks of preeclampsia and perinatal complications. N Engl J Med 2006;354:1796-06.

10. Poston L, Briley AL, Seed PT, Kelly FJ, Shennan AH. Vitamins in Pre-eclampsia (VIP) Trial Consortium. Lancet 2006;367:1145-54.

11. Askie LM, Duley L, Henderson-Smart DJ, Stewart LA on behalf of the PARIS Collaborative Group. Antiplatelet agents for prevention of pre-eclampsia: a meta-analysis of individual patient data. Lancet 2007;369:1791-98.

12. Snijders RJ, Noble P, Sebire N, Souka A, Nicolaides KH. UK multicentre project on assessment of risk of trisomy 21 by maternal age and fetal nuchal translucency thickness at 1014 weeks of gestation. Lancet 1998;351:343-46.

13. Nicolaides KH. Nuchal translucency and other first-trimester sonographic markers of chromosomal abnormalities. Am J Obstet Gynecol 2004;191:45-67.

14. Martin AM, Bindra R, Curcio P, Cicero S, Nicolaides KH. Screening for pre-eclampsia and fetal growth restriction by uterine artery Doppler at 11-14 weeks of gestation. Ultrasound Obstet Gynecol 2001;18:583-86.

15. Harrington KF, Campbell S, Bewley S, Bower S. Doppler velocimetry studies of the uterine artery in the early prediction of pre-eclampsia and intra-uterine growth retardation. Eur J Obstet Gynecol Reprod Biol. 1991;42:14-20.

16. Aardema M W, Saro M C S, Lander M, De Wolf BTM et al. Second trimester Doppler ultrasound screening of the uterine arteries differentiates between subsequent normal and poor outcomes of hypertensive pregnancy: two different pathophysiological entities?. Clin Sci (Lond). 2004; 106(4):377-82.

17. North RA, Ferrier C, Long D, Townend K, Kincaid-Smith P. Uterine artery Doppler flow velocity waveforms in the second trimester for the prediction of preeclampsia and fetal growth retardation. Obstetrics and Gynecology. 1994; 83(3): 378-86.

18. Coleman MAG, McCowan LME, North RA. Mid-trimester uterine artery Doppler screening as a predictor of adverse pregnancy outcome in high-risk women. Ultrasound in Obs \& Gynecol. 2000;15:7-12. 